\title{
Avaliação da reação de genótipos de soja ao oídio em diferentes condições. *
}

\author{
Elaine Cristine Piffer Gonçalves ${ }^{1}$, Maria Aparecida Pessoa Cruz Centurion ${ }^{2} \&$ Antonio Orlando Di Mauro ${ }^{2}$.
}

\begin{abstract}
${ }^{1}$ Pesquisadora Científica APTA- Alta Mogiana. Avenida Rui Barbosa, s/n. Caixa Postal 35, Colina, SP, Brasil, e-mail: elainegoncalves@sp.gov.br. (2) Pro fessor - UNESP - Campus de Jaboticabal. Via de Acesso Prof. Paulo Donato Castellane, Km 5, 14870-000 Jaboticabal, SP, Brasil. * Parte do trabalho de graduação da primeira autora. ** Trabalho financiado pela FAPESP.
\end{abstract}

Autora Correspondente: Elaine Cristine Piffer Gonçalves

Data de chegada: 01/02/2007. Aceito para publicação em: 01/12/2008

\section{RESUMO}

E.C.P.Gonçalves, M.A.P.C.Centurion \& A.O. Di Mauro. Avaliação da reação de genótipos de soja ao oídio em diferentes condições.Sum ma Phytopathologica, v.35, n.2, p.151-153, 2009

O presente trabalho teve como objetivo avaliar a reação de genótipos de soja ao oídio em diferentes condições: casa-devegetação, campo e laboratório. Foram testados genótipos pertencentes ao programa de Melhoramento do Departamento de Produção Vegetal da FCAV/UNESP. Foram feitas avaliações da severidade do oídio, de acordo com escala de notas de 0 a 5 , em que: $0=$ folha sem sintomas e $5=$ mais de $75 \%$ de área foliar infectada. Após as avaliações, atribuiu-se a cada genótipo as reações correspondentes, sendo que notas de 0 a 2,0 correspondem à reação de resistência; 2,1 a 3,0 de moderada resistência; 3,1 a 4,0 de suscetibilidade; e 4,1 a 5,0 de alta suscetibilidade. Os resultados obtidos evidenciaram que os genótipos, JB95 50028, JB94 0210 e JB93 54320 apresentaram os menores índices de severidade da doença, em todas as condições testadas.

Palavras-chave adicionais: Glycine max, cultivo da folha destacada, Erysiphe diffusa

\section{ABSTRACT
ABTRA}

E.C.P.Gonçalves, M.A.P.C.Centurion \& A.O. Di Mauro. Evaluation of the reaction of soybean genotypes to powdery mildew in different conditions.Summ a Phytopathologica, v.35, n.2, p.151-153, 2009

The objetive of this work was to evaluate the reaction of soybean genotypes to powdery mildew in different conditions: greenhouse, field and laboratory. The studies were carried out at UNESP - Campus of Jaboticabal. For the three studied conditions evaluations were performed according to $0-5$ scores being: $0=$ leaves without symptoms and $5=$ more than $75 \%$ of leaf area infected. After evaluations, to each genotype was attributed the corresponding reactions as follow: 0 to 2.0 - resistant reaction; 2.1 to 3.0 - moderate resistant; 3.1 to 4.0 - susceptible; and 4.1 to 5.0 - high susceptibility. The result showed that genotypes JB95 50028, JB94 0210 and JB93 54320 had the lower rates for severity at all tested conditions.

Keywords: Glycine max, culture of the detached leaf, Erysiphe diffusa.

A soja é uma importante leguminosa no Brasil, que se destaca no cenário mundial como o segundo maior produtor e exportador de grãos (1). Entre os fatores que limitam a obtenção de maiores rendimentos na cultura, destaca-se o grande número de doenças (5). A partir da safra de 1996/97, a doença conhecida como oídio tornou-se alvo de estudos, uma vez que provocou quedas de até $40 \%$ na produção, favorecida por clima chuvoso e temperaturas amenas. O oídio, causado por Erysiphe diffusa é facilmente reconhecido por formar colônias esbranquiçadas sobre a superfície dos órgãos da planta de soja (4). Sob condições de infecção severa, além do dano direto ao tecido da planta provocado pelo parasitismo, todos os órgãos da planta ficam recobertos pelas estruturas (micélio e frutificação) do fungo, o que prejudica a fotossíntese. Em conseqüência, folhas secam e caem prematuramente, dando à lavoura uma coloração variável de castanhoacinzentada a bronzeada, com aparência de soja dessecada por herbicida $(4,6)$. Considerando que o método de controle mais eficiente das doenças é o emprego de variedades resistentes, os programas de melhoramento passaram a incluir em suas avaliações a reação dos genótipos de soja ao oídio, visando selecionar materiais resistentes à doença. Nessas condições, o presente estudo teve como objetivo avaliar a reação de genótipos de soja ao oídio, em diferentes condições: casade-vegetação, campo e laboratório, utilizando-se a técnica da folha destacada.

Os experimentos em casa-de-vegetação e laboratório foram realizados no Departamento de Produção Vegetal, e os de campo foram conduzidos na área experimental da Fazenda de Ensino e Pesquisa, da UNESP - Câmpus de Jaboticabal. Os genótipos estudados fazem parte do programa de melhoramento que vem sendo desenvolvido no Departamento de Produção Vegetal.

No ensaio de campo (outubro-fevereiro), utilizou-se espaçamento de $50 \mathrm{~cm}$ entrelinhas, deixando-se, após o desbaste, 20 plantas por metro. Cada parcela cons tituiu-se de duas linhas de quatro metros de comprimento. Entre cada parcela foi semeada uma linha da cultivar IAC - Foscarim - 31, que é classificada como altamente suscetível ao oídio, segundo Yorinori (6). O delineamento experimental empregado foi de blocos ao acaso, com três repetições. Foram efetuadas três 
Tabela 1. Nível de infecção e reação dos genótipos ao oídio em folhas destacadas, casa-de-vegetação e campo.

\begin{tabular}{|c|c|c|c|c|c|c|}
\hline \multirow{3}{*}{ Genótipos } & \multicolumn{6}{|c|}{ Oídio } \\
\hline & \multicolumn{2}{|c|}{ Folha destacada } & \multicolumn{2}{|c|}{ Casa de vegetação } & \multicolumn{2}{|c|}{ Campo } \\
\hline & $\mathrm{NI}^{1 /}$ & Reação $^{2 /}$ & $\mathrm{NI}^{1 /}$ & $\mathrm{NI}^{1 /}$ & Reação $^{2 /}$ & $\mathrm{NI}^{1 /}$ \\
\hline JB $95-50028$ & $2,25^{3 /}$ & MR & $2,25^{3 /}$ & MR & $0,87^{4 /}$ & $\mathrm{R}$ \\
\hline JB $95-140022$ & 4,88 & AS & 4,50 & AS & 3,20 & $\mathrm{~S}$ \\
\hline JB 94 - 030224 & 2,45 & MR & 3,50 & $\mathrm{~S}$ & 1,70 & $\mathrm{R}$ \\
\hline JB $95-160002$ & 3,25 & $\mathrm{~S}$ & 4,00 & $\mathrm{~S}$ & 4,00 & $\mathrm{~S}$ \\
\hline JB $94-0210$ & 3,00 & MR & 2,50 & MR & 1,80 & $\mathrm{R}$ \\
\hline JB $94-160601$ & 4,50 & AS & 4,50 & AS & 3,10 & $\mathrm{~S}$ \\
\hline JB $94-140024$ & 3,85 & $\mathrm{~S}$ & 5,00 & AS & 3,90 & $\mathrm{~S}$ \\
\hline JB $93-54320$ & 2,30 & MR & 3,00 & MR & 1,40 & $\mathrm{R}$ \\
\hline JB $95-20029$ & 2,82 & MR & 4,75 & AS & 2,30 & MR \\
\hline JB $95-900$ & 4,45 & AS & 5,00 & AS & 3,10 & $\mathrm{~S}$ \\
\hline JB 94 - 1104 & 3,23 & $\mathrm{~S}$ & 5,00 & AS & 3,50 & $\mathrm{~S}$ \\
\hline JB $95-20023$ & 2,62 & MR & 4,75 & AS & 3,30 & $\mathrm{~S}$ \\
\hline JB $94-1608$ & 4,95 & AS & 3,75 & $\mathrm{~S}$ & 4,00 & $\mathrm{~S}$ \\
\hline JB $95-130021$ & 3,20 & $\mathrm{~S}$ & 4,00 & $\mathrm{~S}$ & 2,30 & MR \\
\hline JB $95-160025$ & 3,20 & $\mathrm{~S}$ & 4,25 & AS & 3,30 & $\mathrm{~S}$ \\
\hline FT Estrela ${ }^{5 /}$ & 4,50 & AS & 5,00 & AS & - & - \\
\hline MG/BR-46 (Conquista) 6/ & 2,98 & MR & 3,50 & $\mathrm{~S}$ & - & - \\
\hline IAC-Foscarim-31 $7 /$ & - & - & - & - & 5,00 & AS \\
\hline
\end{tabular}

${ }^{1 /}$ Nível de infecção: nota $0=$ ausência de sintomas; 1 = traços até $10 \%$ da área foliar infectada; $2=11$ a $25 \%$ da área foliar infectada; $3=26$ a $50 \%$ da área foliar infectada; $4=51$ a $75 \%$ da área foliar infectada; $5=$ mais de $75 \%$ da área foliar infectada

${ }^{2 /} \mathrm{R}=$ resistente $(\mathrm{NI}=0$ a 2$) ; \mathrm{MR}=$ moderadamente resistente $(2,1$ a 3,0$) ; \mathrm{S}=\operatorname{suscetível}(3,1$ a 4,0$) ; \mathrm{AS}=$ altamente suscetível $(4,1$ a 5,0$)$

${ }^{3 /}$ Média de quatro repetições
Més

${ }^{4 /}$ Média de três repetições, sendo que em cada repetição foram feitas avaliações em três pontos

5/ Padrão de suscetibilidade utilizado nos ensaios de folha destacada e casa de vegetação

${ }^{6 /}$ Padrão de resistência utilizado nos ensaios de folha destacada e casa de vegetação

${ }^{7 /}$ Padrão de suscetibilidade no ensaio de campo.

avaliações da severidade do oídio, sendo a primeira, quando as plantas se encontravam no estádio $R_{1}(2)$, a segunda, nos estádios $R_{2}, R_{3}$ ou $\mathrm{R}_{4}$, em função do ciclo do genótipo, e a terceira, nos estádios $\mathrm{R}_{5}, \mathrm{R}_{6} \mathrm{ou}$ $\mathrm{R}_{7}$.

Em casa-de-vegetação, o delineamento utilizado foi em blocos ao acas o, com quatro repetições, sendo cada parcela constituída por um vaso contendo cinco plantas.

Os mesmos genótipos usados no teste em vasos foram semeados em folhas destacadas, assim como as cultivares utilizadas como padrão de resistência e suscetibilidade MG/BR 46 (Conquista) e FT - Estrela, respectivamente. Entre os vasos dos genótipos testados foram distribuídos vasos com a cultivar altamente suscetível IAC-Fosc arim 31, apresentando sintomas de oídio, para que a infecção natural ocorresse de forma rápida e uniforme. Foram incluídas neste ensaio, como padrão de resistência e suscetibilidade, as cultivares MG/BR 46 (Conquista) e FT-Estrela, resistente e susc etível, respectivamente.

Para o ensaio de laboratório, folhas utilizadas para os testes, foram destacadas das plantas de soja cultivadas em casa-de-vegetação, de acordo com metodologia descrita por Gonçalves (3). As folhas foram inoculadas utilizando-se o método da exposição da folha destacada ao inóculo descrito por Gonçalves (3). A incubação das folhas destacadas inoculadas foi feita em câmara de germinação, na temperatura de aproximadamente $22^{\circ} \mathrm{C}$, e fotoperíodo de 12 horas. $\mathrm{O}$ delineamento utilizado foi inteiramente casualizado, com quatro repetições, sendo cada parcela representada por uma placa de Petri contendo duas folhas destacadas de soja. Para cada tratamento, incluiuse uma tes temunha não inoculada.

A avaliação da severidade da doença, foi realizada por meio de uma escala de notas de 0 a 5 , sendo que: $0=$ folha sem sintomas, $1=$ traços a $10 \%$ da superfície foliar ino culada com sintomas, $2=11$ a $25 \%$ da superfície foliar inoculada com sintomas, $3=26$ a $50 \%$ da superfície foliar inoculada com sintomas, $4=51-75 \%$ da superfície foliar inoculada com sintomas, 5 = mais de $75 \%$ da superfície foliar inoculada com sintomas.

Pode-se observar na Tabela 1 que os genótipos que apresentaram os melhores resultados, em condições de campo, foram JB 95- 50028, JB 94- 030224, JB 94- 0210 e JB 93- 54320, sendo classificados como resistentes ao oídio, de acordo com os níveis de infecção e reações propostas por Yorinori (6). Os genótipos JB 95- 20029 e JB 95130021 foram classificados como moderadamente resistentes. Por outro lado, em condições de casa-de-vegetação, os genótipos que apresentaram maior nível de resistência foram JB 95- 50028, JB 940210, com reação moderadamente resistente e JB 93- 54320, que apresentou reação de resistência ao oídio. Já nas avaliações de folhas destacadas, os genótipos que apresentaram os melhores resultados foram JB 95- 50028, JB 94- 030224, JB 94- 0210, JB 93- 54320, JB 95- 20029, JB 95- 20023 e a cultivar MG/BR-46 (Conquista), sendo classificados como moderadamente resistentes.

As variações que ocorreram nos níveis de infecção e reações dos genótipos nas diferentes condições testadas (folha destacada, casa- 
de-vegetação e campo), podem ser explicadas por várias causas, dentre elas, podem-se citar: as diferentes épocas de instalação dos experimentos, sendo a época de condução dos experimentos em condições de casa de vegetação (julho a outubro), considerada mais propícia para o desenvolvimento do oídio do que a época em que o ensaio foi conduzido a campo. No ensaio de folha destacada, a temperatura constante de $22^{\circ} \mathrm{C}$, é também uma condição mais favorável do que as altas temperaturas que ocorrem em condições de campo, na época convencional de cultivo de soja.

\section{REFERÊNCIAS BIBLIOGRÁFICAS}

1. Soja Agrianual 2006: Anuário da Agricultura Brasileira, São Paulo, p.433-468, 2005.
2. Fehr, W.R.; Caviness, J.A. Stages of soybe an devel opment. Ammes, Yowa: Yowa State University, Cooperative Extension Service, 1977. 11p. (Special Report, 80).

3. Gonçalves, E.C.P. Genética da resistência da soja ao oídio (Microsphaera diffusa) e correlação entre duas metodologias de avaliação. 56f. 2002. Dissertação Mestrado em Genética e Melhoramento de Plantas - Universidade Estadual Paulista, Faculdade de Ciências Agrárias e Veterinárias, Jaboticabal.

4. Sartorato, A.; Yorinori, J. T. Oídios de Leguminosas: Feijoeiro e Soja. In: Stadnik, M.J.; Rivera, M. C. Oídi os. Jaguariúna: Embrapa Meio Ambiente, 2001. 484p.

5. Yorinori, J.T. Cancro da haste da Soja:epidemiologia e controle. Londrina: Embrapa, CNPSo, 1996. 75p. (Circular Técnica, 14).

6. Yorinori, J.T. Oídio da Soja. Londrina:Embrapa Soja. 1997. 13p. (Documentos, 13) 